\title{
Depoimento Especial a partir de Opiniões de Psicólogos Brasileiros Atuantes nessa Prática
}

\author{
Janaina Alessandra da Silva Sanson ${ }^{1}$ \\ Jean Von Hohendorff \\ ${ }^{1} I M E D$, Passo Fundo, Rio Grande do Sul, Brasil
}

\begin{abstract}
Resumo
O Depoimento Especial (DE) é uma prática de oitiva de crianças e adolescentes no âmbito judiciário, normalmente acompanhado por psicólogos. Objetivou-se conhecer opiniões de psicólogos brasileiros que atuavam no DE sobre essa prática. Foi realizada uma pesquisa qualitativa exploratória transversal on-line, por meio de ferramentas digitais (e.g., Skype, Whatsapp). Dez psicólogos brasileiros, de seis diferentes estados, atuantes no DE, responderam a uma ficha de dados sociodemográficos e a uma entrevista semiestruturada. As entrevistas foram estudadas a partir da análise temática. Evidenciaram-se seis temas, sendo eles: papel profissional, trabalho interdisciplinar, sentimentos, agilidade, proteção e legislação. Tomados em conjunto, esses temas indicam o DE como ágil e protetivo para as crianças e adolescentes vítimas de violência sexual, salientando possíveis desafios à sua efetivação. Os resultados obtidos possibilitam maior conhecimento sobre a prática do DE e podem ser utilizados em futuras revisões dessa prática.

Palavras-chave: maus-tratos infantis, violência sexual, defesa da criança e do adolescente, depoimento especial
\end{abstract}

Views of Brazilian Psychologists on Children's Testimony

\begin{abstract}
Special Testimony is a method of judicial hearing of children and adolescents in Brazil, usually accompanied by psychologists. The objective of the present study was to know the opinions of Brazilian psychologists who work with children's testimony about this practice. A cross-sectional exploratory qualitative research was conducted using digital tools such as Skype and Whatsapp. A total of 10 Brazilian psychologists, from six different states, working with Special Testimony completed a sociodemographic questionnaire and a semi-structured interview. The interviews were analyzed according to the Thematic Analysis. Six themes were highlighted: professional role, interdisciplinary work, feelings, swiftness, protection, and legislation. Taken together, these themes indicate that the Special Testimony is swift and protective for children and adolescents victims of sexual violence, highlighting possible challenges to its implementation. The results obtained provided more knowledge about the Special Testimony and can be used in future revisions of this practice.

Keywords: child abuse; sexual violence; child and adolescent defense; children's testimony
\end{abstract}

\section{Testimonio Especial a partir de las Opiniones de Psicólogos \\ Brasileños que Actúan en esta Práctica}

\section{Resumen}

El Testimonio Especial (DE) es una práctica de escucha de niños y adolescentes en el ámbito judicial, generalmente, acompañados por psicólogos. La finalidad fue conocer las opiniones de psicólogos brasileños, que trabajan con el Testimonio Especial sobre esta práctica. Se realizó una investigación cualitativa exploratoria transversal en línea utilizando herramientas digitales (e.g., Skype, WhatsApp). Diez psicólogos brasileños actuantes en el DE, provenientes de seis diferentes provincias, respondieron a una ficha de datos sociodemográficos y una entrevista semiestructurada. Las entrevistas se analizaron a partir del análisis temático, destacando seis temas: rol profesional, trabajo interdisciplinario, sentimientos, agilidad, protección y legislación. En conjunto, estos temas apuntaron el DE como ágil y protectivo para los niños y adolescentes víctimas de violencia sexual, evidenciando posibles retos para su implementación. Los resultados obtenidos posibilitan un mayor conocimiento sobre la práctica del Testimonio Especial y pueden ser utilizados en futuras revisiones de esta práctica.

Palabras clave: abuso infantil; violencia sexual; protección del niño y del adolescente; testimonio especial

\section{Introdução}

A revelação de violência sexual realizada por uma criança ou adolescente vítima nem sempre é recebida com credibilidade pela família e pela sociedade em geral. Summit (1983) propôs a ocorrência da chamada Síndrome da Acomodação para auxiliar na compreensão da posição da criança ou adolescente frente à complexa dinâmica da violência sexual contra eles. Cinco categorias estão presentes nessa síndrome: (a) segredo; (b) desamparo; (c) acomodação; (d) revelação tardia e pouco convincente e (e) retratação. Essas categorias foram propostas pelo autor a partir da sua prática clínica e demonstram a dificuldade da revelação. 
Fatores como o desconhecimento da vítima sobre a prática sexual imposta a ela, bem como chantagens e ameaças dos agressores contribuem para a manutenção do segredo. A vítima percebe-se desamparada tendo em vista que um/a adulto/a de confiança está a violentando e/ou pode buscar ajuda e não recebê-la. Assim, pode se acomodar a situação, por não perceber alternativa, o que acaba resultando em uma revelação tardia que, muitas vezes, é seguida de uma retratação diante da pressão dos agressores e familiares.

Após a revelação e notificação, a vítima é encaminhada para diferentes serviços, nos âmbitos protetivos e de atendimento. Dentre esses serviços, o judiciário tem a atribuição de proteger a vítima e responsabilizar o/a agressor/a. Para tal, a oitiva da vítima é necessária, além de ser um direito da criança ou do adolescente, conforme previsto no artigo 12 da Convenção sobre os Direitos da Criança (Brasil, 1990b).

A oitiva de crianças e adolescentes não é uma tarefa simples para o sistema judiciário. O despreparo dos profissionais do Direito em lidar com esse tipo de situação dificulta a garantia de proteção desse público, reforçando a sua vulnerabilidade, além de comprometer a possibilidade de confirmação da ocorrência da violência (Caribé \& Lima, 2015). Além disso, a inadequação do espaço físico das salas de audiências foi determinante para a criação de um formato diferenciado para crianças e adolescentes, denominado Depoimento Especial (DE). Os ambientes das salas de audiência eram "formais e frios" (p. 19), dificultando que as crianças e adolescentes se sentissem à vontade em suas oitivas (Daltoé, 2007).

O DE consiste em realizar a oitiva da criança ou do adolescente em um ambiente separado da sala de audiências, onde se encontram a vítima e um/a profissional capacitado/a, geralmente psicólogo/a ou assistente social, que irá realizar a entrevista. A sala é provida de câmeras e microfones para a gravação desse depoimento. O DE é realizado a partir de um circuito fechado de televisão (Closed Circuit Television-CCVT), de forma com que o/a reú/ré, o/a magistrado/a e os demais operadores do Direito assistam ao depoimento em tempo real na sala de audiências (Santos \& Gonçalves, 2009). O/a psicólogo/a ou assistente social possui um ponto eletrônico em seus ouvidos, permitindo a interação com os profissionais presentes na sala de audiências. Além de resguardar o direito da criança e do adolescente, essa oitiva prevê o direito ao contraditório e à ampla defesa por parte do/a réu/ré (Daltoé, 2007). Para sua adequada efetivação, necessita de técnicos preparados para a condução de entrevistas sem uso de perguntas inapropriadas (Pelisoli, Dobke, \& Dell'aglio, 2014).

A prática do DE tem três principais objetivos: diminuição dos danos sofridos pelas crianças e adolescentes que foram vítimas ou testemunhas de violência, prezar pela garantia de direitos, proteção desse público e avanço na elaboração da prova (Daltoé, 2007). Sendo assim, segundo a Lei n. 13.431/2017, o DE, sempre que possível, será realizado uma única vez, visando que não seja necessário que a vítima repita seu relato (Brasil, 2017). Além disso, a obtenção de provas materiais, em casos de violência sexual, nem sempre é possível, conferindo maior relevância ao depoimento da vítima (Caribé \& Lima, 2015).

No entanto, a prática do DE vem gerando discussões desde sua criação, em 2003. Alguns questionamentos sobre o DE foram levantados, entre eles, a divergência entre direito e dever da fala das crianças ou adolescentes (Brito, 2008). Refletem também a possível desvalorização do dano causado à criança ou ao adolescente pelo evento vivido e o seu relato, enfatizando a obtenção de prova para sentença do/a acusado/a (Conselho Federal de Psicologia [CFP], 2010a).

Além desses questionamentos, não há consenso sobre a função do/a psicólogo/a na prática do DE. Os posicionamentos a favor da prática indicam que os psicólogos são os profissionais mais capacitados para essa escuta, pois possuem conhecimentos sobre o desenvolvimento humano, técnicas de entrevista e sobre dinâmica de violência (Pelisoli et al., 2014). Porém, o posicionamento contrário evidencia que a atuação do/a psicólogo/a na prática do DE não tem o intuito de avaliação ou atendimento psicológico, mas sim objetiva a obtenção de prova por meio da fala da criança ou adolescente (Brito, 2008).

O CFP mostrou-se contrário à atuação do/a psicólogo/a no DE. Argumentou-se que o DE se caracteriza como uma prática de violação dos direitos humanos, uma vez que objetiva, especialmente, a obtenção da prova judicial em detrimento da escuta especializada de crianças e adolescentes (CFP, 2010a). Sendo assim, na Resolução n. 010/2010, o CFP determinou ser vedado aos psicólogos adequarem-se como inquiridores na escuta de crianças e adolescentes (CFP, 2010b). Isso porque na busca de penalização dos supostos agressores, que na maioria dos casos têm relação afetiva com a vítima, não se considera totalmente as consequências do relato na vida da criança ou do adolescente (CFP, 2010a). Porém, com o objetivo de suspensão da aplicação e 
das consequências da Resolução n. 010/2010 (CFP, 2010b) no país, o Ministério Público Federal e o Ministério Público do Rio de Janeiro ingressaram com uma ação civil pública (n. 0008692-96.2012.4.02.5101), com pedido de liminar. A liminar foi deferida, garantindo aos psicólogos a atuação no DE sem possibilidade de qualquer penalização pelo CFP (Pelisoli et al., 2014). A ação foi julgada no ano de 2016, impedindo que os conselhos de Psicologia pró́bissem a atuação de psicólogos no DE (Tribunal Regional Federal da $2^{\mathrm{a}}$. Região, 2016).

Desde 2003, a prática do DE ocorria conforme a decisão dos magistrados e a disponibilidade da estrutura física de equipamentos disponíveis nos Tribunais de Justiça. No entanto, recentemente, foi aprovada a Lei n. 13.431 (Brasil, 2017), que estabelece o sistema de garantia de direitos para crianças e adolescentes que foram vítimas ou testemunhas de violência. Essa Lei altera a Lei n. 8.069 (i.e., Estatuto da Criança e do Adolescente [ECA], Brasil, 1990a). Entre outras formas de resguardar os direitos das crianças e dos adolescentes, a Lei n. 13.431 (Brasil, 2017) versa sobre o reconhecimento da necessidade de uma escuta especializada na rede de proteção e o DE em âmbito jurídico ou policial, realizada por profissionais capacitados para tal tarefa. Sendo assim, a partir de 04 de abril de 2018 , são permitidas somente oitivas de crianças e adolescentes com base nessa prática (i.e., DE).

Diante da aprovação da lei, o CFP emitiu Nota Técnica n¹/2018/GTEC/CG (i.e., nota técnica sobre os impactos da Lei n. 13.431 (Brasil, 2017) na atuação das psicólogas e dos psicólogos). O CFP pontuou algumas críticas à nova legislação (e.g., ausência de debates públicos antes da aprovação da lei e ausência de estratégias de prevenção à violência contra crianças e adolescentes). Por fim, recomendou que os psicólogos não atuem no DE, enfatizando que devem basear suas atuações profissionais de acordo com o Código de Ética da categoria (CFP, 2018).

As discussões sobre o DE indicam, portanto, diferentes opiniões sobre a sua pertinência. O CFP mostra-se contrário à atuação de psicólogos nessa prática, enquanto a aprovação da Lei n. 13.431 (Brasil, 2017) institui o DE como prática de oitiva de crianças e adolescentes no judiciário. Sendo assim, considera-se que aqueles que atuam diariamente com o DE de fato o conheçam (Pelisoli \& Dell'aglio, 2016), podendo fornecer informações sobre a adequação ou não da prática. Diante disso, buscou-se conhecer a opinião dos profissionais da Psicologia que atuam com a prática do DE sobre essa prática.

\section{Método}

\section{Participantes}

Participaram oito psicólogas e dois psicólogos brasileiros, com idades entre 33 e 56 anos $(M=39,6$; $D P=6,9)$, brancos $(n=8)$ e pardos $(n=2)$, casados $(n$ $=5)$, solteiros $(n=4)$ e separado $(n=1)$. As titulações máximas dos participantes foram pós-graduação Lato Sensu $(n=5)$, mestrado $(n=3)$ e doutorado $(n=2)$. Os participantes realizavam a prática do $\mathrm{DE}$ nos estados do Rio Grande do Sul $(n=2)$, Paraná $(n=3)$, São Paulo $(n=1)$, Rio de Janeiro $(n=1)$, Distrito Federal $(n=2)$ e Pernambuco $(n=1)$, atuando em tribunais de justiça $(n=4)$, fóruns $(n=3)$, varas da infância e da juventude $(n=2)$ e serviço de apoio à infância e juventude do judiciário $(n=1)$, nas funções de psicólogos jurídicos $(n=6)$, analistas judiciários $(n=3)$ e técnica judiciária $(n=1)$.

\section{Instrumentos}

Ficha de dados sociodemográficos. Ficha elaborada para utilização neste estudo, visando caracterizar os participantes. As informações coletadas foram as seguintes: estado, idade, cor, estado civil, serviço que trabalha, titulação máxima, função no serviço e tempo na função.

Roteiro de entrevista semiestruturado. Roteiro elaborado para utilização neste estudo durante as entrevistas on-line. Conteve sete questões norteadoras, sendo elas: "Descreva o seu trabalho no Depoimento Especial", "Comente qual é a sua opinião referente à prática do DE”, “Como se deu sua inserção no DE?”, "Descreva as relações entre a Psicologia e os demais membros da equipe do DE", "Qual é a sua opinião sobre a legislação acerca da escuta de crianças e adolescentes pelo judiciário?", "Qual a sua avaliação geral do Depoimento Especial? ", "Se possível, você mudaria algo no DE? O que e por quê?"

\section{Procedimentos de Coleta de Dados}

O projeto foi aprovado por um Comitê de Ética em Pesquisa (CAAE n. 70421417.0.0000.5319). Em seguida, buscou-se o contato de possíveis psicólogos participantes por indicações a partir da rede de contatos dos pesquisadores. A intenção era a de atingir o número total de psicólogos que realizam o DE no território nacional. Porém, sabendo que esse número é desconhecido, trabalhou-se com o maior número possível de participantes durante o período de coleta de dados. Foi feito contato via e-mail com profissionais do judiciário do Rio Grande do Sul, solicitando indicação 
de participantes. Foram recebidas oito indicações de contatos, destas, apenas três aceitaram participar da pesquisa. Após, foram acessados outros participantes por indicações desses entrevistados, conseguindo mais um participante. Os demais foram contatados a partir de um grupo de Whatsapp no qual profissionais de Tribunais de Justiça do país interagem.

Os pesquisadores foram inclusos nesse grupo de Whatsapp por um profissional que trabalha em um Tribunal de Justiça, que foi contatado pelos pesquisadores a fim de solicitar auxílio na indicação dos participantes. O número total de contatos foi de 24 possíveis participantes. Destes, foram realizadas entrevistas com 11, porém uma das entrevistas precisou ser excluída, pois a profissional não atuava com o DE. Os 13 contatos restantes não participaram da pesquisa por motivos individuais (e.g., dificuldade de horários, não responderam aos e-mails, desconforto em participar da pesquisa).

Todos os participantes foram questionados quanto ao seu interesse em participar da pesquisa, explicando-se os objetivos e procedimentos e foi solicitado seu consentimento verbal. De acordo com a Resolução n. 510/2016 (Conselho Nacional de Saúde, 2016), o processo de consentimento livre e esclarecido perpassa toda a etapa de coleta de dados. O registro do consentimento livre e esclarecido pode, então, ser feito em qualquer meio (e.g., papel, áudio, filmagem). Nesta pesquisa, o registro foi por meio de áudio dos participantes, tendo em vista que se tratava de uma coleta de dados on-line.

Considerando que os participantes foram de diferentes regiões do Brasil, a coleta de dados foi realizada por meio de ferramenta digital on-line (e.g., Skype e Whatsapp), sendo gravada para posterior transcrição e análise de dados. A ordem de coleta de dados foi a seguinte: (1) questões da ficha de dados sociodemográficos; (2) entrevista semiestruturada. Alguns métodos qualitativos vêm se adaptando ao uso da internet como ferramenta. Sendo assim, a pesquisa qualitativa on-line é utilizada quando a entrevista presencial possa causar apreensão aos participantes em responder uma série de perguntas ou quando os pesquisadores não têm acesso a todos os participantes de forma presencial (Flick, 2009).

\section{Procedimentos de Análise de Dados}

Foi realizada a transcrição das emissões verbais dos participantes. Utilizou-se a técnica de Análise Temática proposta por Braun e Clarke (2006), que é constituída por seis etapas: (a) Familiarização: transcrição dos dados, leituras repetidas da transcrição e anotações; (b) Identificação de códigos iniciais: São produzidos códigos iniciais, ou seja, trechos do material são selecionados e nomeados de acordo com o seu conteúdo; (c) Procura por temas: identificação de temas entre os códigos; (d) Revisão dos temas: os temas são refinados, podendo ser agrupados, divididos ou excluídos; (e) Definição e nomeação dos temas: nomeia-se os temas e descreve-se o conteúdo de cada tema; e (f) Produção do relatório: após a finalização dos temas, são executadas a análise final e a redação do relatório. Todas as etapas de análise foram realizadas pela primeira autora, sendo que as etapas $c$, d, e e $\mathrm{f}$ foram discutidas e revisadas com o segundo autor, visando dirimir dúvidas e ajustes necessários.

\section{Resultados}

$\mathrm{Na}$ apresentação dos resultados, os participantes serão indicados pelos números correspondentes à ordem numérica das entrevistas realizadas (1 a 10). A análise dos dados de acordo com a proposta de análise temática de Braun e Clarke (2006) resultou em seis temas e 12 subtemas (ver Tabela 1). As frases citadas na Tabela 1 foram citações dos participantes, escolhidas por melhor expressarem o conteúdo de cada subtema.

O tema Papel Profissional se refere às opiniões dos participantes a respeito dos papéis profissionais dos membros envolvidos na prática do DE. Esse tema possui os seguintes subtemas: Formação, Psicologia, Identificação com o DE, Protocolos de entrevista, Autonomia do/a psicólogo/a e Direito.

O subtema Formação contém os posicionamentos dos participantes sobre a formação técnica dos entrevistadores do DE. Alguns participantes (2 e 8) relataram não ser papel específico da Psicologia realizar o DE. Relataram considerar adequada a atuação de outros profissionais desde que tenham capacitação técnica necessária. Porém, apesar de compreender que não é uma tarefa exclusiva dos psicólogos, uma participante (8) verbalizou acreditar que os psicólogos são os profissionais mais adequados para atuarem no DE, pois adquirem, desde a graduação, os requisitos necessários para essa atuação (i.e., técnicas de entrevista, rapport, vinculação). Entretanto, dois participantes (4 e 10) indicaram ser uma função específica da Psicologia, desconsiderando outras profissões nessa atuação. Contudo, mesmo considerando os psicólogos como profissionais mais adequados para conduzir a entrevista no DE, os participantes (1 e 8) apontaram não considerar suficiente a graduação em Psicologia, sendo necessário ter 
Tabela 1.

Temas e Subtemas

\begin{tabular}{|c|c|c|}
\hline Temas & Subtemas & Exemplos \\
\hline \multirow{6}{*}{$\begin{array}{l}\text { Papel } \\
\text { profissional }\end{array}$} & Formação & $\begin{array}{l}\text { Eu sinceramente acho que nós psicólogos fazemos melhor } \\
\text { tecnicamente }[\ldots . .] \text { a gente faz melhor em todos os sentidos } \\
\text { (8). }\end{array}$ \\
\hline & Psicologia & $\begin{array}{l}\text { Ouvir com interesse, com empatia, o respeito profundo que } \\
\text { a gente estabelece [...], durante uma escuta de um assunto tão } \\
\text { sensível, eu acho que pode ter um efeito sobre a criança (7). }\end{array}$ \\
\hline & Identificação com o DE & $\begin{array}{l}\text { Tem pessoas que se identificam e fazem bem feito o DE, } \\
\text { gostam de fazer ( } 8 \text {. }\end{array}$ \\
\hline & Protocolos de entrevista & $\begin{array}{l}\text { A gente segue, o NICHD [National Institute of Child Health } \\
\text { and Human Development] ele é um protocolo bem rígido e } \\
\text { estruturado, mas eu acho que essa parte é bem legal, de você } \\
\text { fazer algumas perguntas pra puxar a memória da criança, aí } \\
\text { elas vão lembrando e, às vezes, já vão contando (7). }\end{array}$ \\
\hline & Autonomia do/a psicólogo/a & $\begin{array}{l}\text { Como a juíza me deu liberdade pra poder fazer a } \\
\text { transformação, eu vou abordar o tema [...] que eles estão } \\
\text { colocando, de uma maneira que seja menos prejudicial (7). }\end{array}$ \\
\hline & Direito & $\begin{array}{l}\text { A gente percebeu que os advogados começaram a falar de } \\
\text { uma maneira mais respeitosa com essas vítimas (2). }\end{array}$ \\
\hline \multirow{3}{*}{$\begin{array}{l}\text { Trabalho } \\
\text { Interdisciplinar }\end{array}$} & Psicologia e Direito & $\begin{array}{l}\text { Varia muito do profissional do Direito [...], essa relação ela } \\
\text { é marcada por como o operador do Direito trata a equipe } \\
\text { técnica (5). }\end{array}$ \\
\hline & Reconhecimento da Psicologia & $\begin{array}{l}\text { O juiz é uma pessoa muito aberta e acessível, ele fala o } \\
\text { conhecimento psicológico quem tem são vocês, vocês que } \\
\text { tem que me falar como que é, como que funciona (4). }\end{array}$ \\
\hline & Integração da rede & $\begin{array}{l}\text { A gente entende que existe uma necessidade de capacitar } \\
\text { todas as pessoas que trabalham com crianças desde } \\
\text { professores, profissionais da saúde, policiais, Conselho } \\
\text { Tutelar pra que diante dessa situação tentem colher o mínimo } \\
\text { de informações necessárias pra dar continuidade ao caso (2). }\end{array}$ \\
\hline Sentimentos & - & $\begin{array}{l}\text { Eu fico muito angustiada porque sou eu que vivencio ali o } \\
\text { sofrimento daquela criança (4). }\end{array}$ \\
\hline \multirow[t]{2}{*}{ Agilidade } & Antecipação da oitiva & $\begin{array}{l}\text { A média era } 2 \text { anos depois dos fatos, e agora a gente } \\
\text { consegue, pelo menos dentro do mesmo mês, fazer essa } \\
\text { entrevista (1). }\end{array}$ \\
\hline & Responsabilização dos agressores & $\begin{array}{l}\text { E esse relato é importante pra questão dos trâmites legais, } \\
\text { inclusive pra uma possível punição do acusado (3). }\end{array}$ \\
\hline Proteção & - & $\begin{array}{l}\text { É um método que procura proteger a criança de ter que } \\
\text { revelar essa experiência de violência em um contexto que não } \\
\text { seja apropriado pra ela, por exemplo, uma sala de audiência } \\
\text { (6). }\end{array}$ \\
\hline Legislação & Posicionamento CFP & $\begin{array}{l}\text { Eu acho tão sem sentido, essa briga entre os conselhos de } \\
\text { classe e a justiça sobre se determinada categoria profissional } \\
\text { pode ou não fazer o DE (6). }\end{array}$ \\
\hline
\end{tabular}

Nota. Cada número, após os trechos, indica o/a respectivo/a participante. 
formações específicas para tal atuação (i.e., dinâmica de violência sexual, técnicas de entrevista) e a contínua qualificação na área.

O subtema Psicologia retrata a postura dos psicólogos na prática do DE. Os participantes $(6,7$ e 8$)$ relataram que a postura de continência do/a psicólogo/a na atuação do DE traz consequências positivas para as crianças e adolescentes que estão sendo ouvidas. Relataram que ouvir com interesse e empatia pode tornar a fala da vítima algo terapêutico. Uma participante (8) relatou considerar que essa postura, além de proporcionar um relato mais empático e acolhedor para as crianças e adolescentes, também constrói uma resiliência para o profissional lidar com a situação de forma tranquila. Nesse sentido, uma participante (10) relatou ser esse o objetivo da Psicologia: proteger as crianças e os adolescentes que precisam ser ouvidos no judiciário.

O subtema Identificação com o DE corresponde aos relatos dos participantes sobre suas percepções acerca do DE e a importância da identificação do profissional com essa função. Três participantes (5, 9 e 10) relataram resistência em atuar no DE, por acreditarem que a prática tirava muito da autonomia do profissional. Quanto à identificação do profissional com essa atuação, uma participante (8) enfatizou ser algo necessário, impactando diretamente a qualidade do trabalho, pois, quando o profissional não se sente bem atuando no $\mathrm{DE}$, isso pode prejudicar o momento da oitiva, tanto para o profissional como para a vítima.

O subtema Protocolos de entrevista se refere à utilização desses instrumentos pelos profissionais entrevistados na condução do DE. A maioria dos participantes $(1,4,5,6,7,8$ e 9) indicaram utilizar protocolos de entrevista na oitiva de crianças e adolescentes. Mesmo utilizando esses protocolos estruturados, uma participante (8) relatou não realizar algumas etapas do protocolo da Entrevista Cognitiva com as crianças e adolescentes, pela compreensão que são adequadas somente para o público adulto e, assim, relatou ser abusivo utilizar com as crianças e adolescentes.

O subtema Autonomia do/a psicólogo/a corresponde às opiniões dos profissionais perante sua autonomia na atuação do DE. Em relação às adaptações das perguntas vindas pelos operadores do Direito para as crianças ou adolescentes, a maioria dos participantes $(1,3,4,6,8$ e 9) relatou ter conquistado sua autonomia profissional. Portanto, indicaram possuir liberdade para adaptar o formato da pergunta com o objetivo de ser menos prejudicial para as crianças e os adolescentes.
Porém, alguns participantes (5 e 7) relataram que, apesar de serem poucas, ainda existem situações em que as adaptações das perguntas não são aceitas pelo judiciário, e o profissional precisa realizá-las no formato em que os operadores do Direito solicitam. Além das adaptações das perguntas, dois entrevistados (1 e 10) indicaram sua autonomia profissional na avaliação prévia ao $\mathrm{DE}$, podendo sugerir, caso julgassem necessário, que a criança ou adolescente vítima não fosse ouvida no formato do DE. Apontaram que, dependendo da idade da vítima ou pelo fato de ela não querer falar, torna-se difícil realizar a entrevista.

O subtema Direito se refere ao papel profissional dos operadores do Direito na prática do DE. As opiniões relatadas pelos participantes foram divergentes. Uma participante (2) relatou que anteriormente a implementação da estrutura técnica do DE, houve adaptações ao processo judicial no formato tradicional, com o objetivo de torná-lo mais humano, capacitando os profissionais do Direito e aproximando-os das crianças e adolescentes. Em contrapartida, três entrevistados $(3,4$ e 8$)$ indicaram que a postura dos operadores do Direito é um fator que precisa ser aperfeiçoado na prática do DE. De acordo com esses participantes, a técnica desses profissionais deveria ser mais "humanizada". Apontaram que os operadores do Direito manteriam uma postura rígida. Além da postura, uma participante (3) salientou a impontualidade dos operadores do Direito ao início do DE como um fator que prejudica a criança ou o adolescente, pois quanto mais tempo a criança ou o adolescente fica aguardando, maior será sua ansiedade e desconforto. Além disso, uma participante (8) relatou considerar fundamental que esses profissionais conheçam as especificidades das três etapas do DE, pois já ocorreram situações em que, na etapa do acolhimento final, a psicóloga foi interrompida por operadores do Direito. A participante relatou, também, que esses profissionais precisam compreender especificidades que a criança ou adolescente possam ter durante sua oitiva como, por exemplo, o silêncio. Contudo, uma participante (9) relatou que, apesar de críticas ao DE indicarem que a postura dos operadores do Direito é de extração da verdade da vítima, ela não percebe isso na prática.

O tema Trabalho Interdisciplinar reflete as opiniões dos participantes sobre a prática do DE na relação com profissionais de outras áreas. Esse tema possui três subtemas: Relação entre Psicologia e Direito, Reconhecimento da Psicologia e Integração da rede. 
O subtema Relação entre Psicologia e Direito diz respeito às duas áreas atuantes no DE. Três participantes $(2,7$ e 8$)$ indicaram dificuldades na relação com o Direito, especificamente quanto ao uso de perguntas inadequadas, principalmente vindas do/a advogado/a de defesa do/a réu/ré. Três participantes $(2,5$ e 8$)$ indicaram que a relação existente entre Psicologia e Direito varia dependendo de cada operador do Direito. Com os profissionais do Direito que valorizam o/a psicólogo/a constitui-se mais trocas de conhecimentos das duas áreas, já os que não valorizam, a relação é demarcada de forma hierárquica. Com relação à existência de uma hierarquia estruturada dentro do judiciário, três participantes (5, 7 e 10) apontaram ser bem delimitada. Porém, uma participante (7) considera que conquistar seu espaço nesse ambiente é um desafio bom, que busca uma parceria com os operadores do Direito.

Mesmo os participantes (5, 7 e 8) que relataram encontrar dificuldades com relação ao trabalho em conjunto com o Direito, indicaram que a relação está melhorando. Verbalizaram que, ao longo do tempo, os operadores do Direito vêm mostrando uma nova percepção sobre os psicólogos e isso é positivo para a relação interdisciplinar. Uma participante (2), no entanto, relatou que não é função de outro profissional (i.e., psicólogo, assistente social) interrogar a vítima. Indicou que, ao colocar outro profissional nessa função, acaba isentando o/a juiz/a, o/a promotor/a e o/a advogado/a dessa tarefa árdua.

Alguns participantes (4, 6, 7, 9 e 10) consideraram ser boa a relação interdisciplinar entre Psicologia e Direito. Compreendem-na como uma parceria entre essas duas áreas que tem objetivos diferentes dentro da prática do DE. Por exemplo, a participante 6 indicou que a Psicologia tem o objetivo de proteger as crianças e os adolescentes e o Direito em exercer o seu papel de responsabilização diante de um crime. Dois participantes $(1,10)$ apontaram ser indispensável uma boa relação para realizar esse trabalho, pois o DE só terá seu funcionamento adequado se os profissionais das duas áreas trabalharem com o mesmo propósito.

Uma participante (10) relatou que os operadores do Direito não têm o dever de saber as especificidades da Psicologia. Indicou que são os psicólogos que devem pontuar a natureza de sua técnica. Por outro lado, relatou esperar que eles sejam receptivos ao conhecimento das funções da Psicologia e possam compreender que se trata de uma disciplina autônoma e não está submetida ao Direito.
Os participantes $(2,5$ e 7$)$ pontuaram suas opiniões sobre possíveis mudanças na relação entre Psicologia e Direito no DE. Indicaram ser necessária a aceitação do judiciário perante as colocações do/a psicólogo/a ao receber as perguntas vindas dos operadores do Direito. Também em relação às perguntas, uma participante (2) relatou ser mais adequado receber as perguntas anteriormente ao DE, para que exista um maior tempo para formulação de tais perguntas e também para que a criança ou adolescente não fique aguardando enquanto o profissional as ouve no fone de ouvido. Além disso, uma participante (5) considerou necessária uma maior interlocução entre psicólogos e profissionais do judiciário após o DE. Indicando que com o conhecimento teórico sobre a complexa dinâmica de violência sexual, o/a psicólogo/a percebe algumas características do relato da criança e adolescente que passam despercebidas pelos profissionais do Direito.

Duas participantes (7 e 8) relataram que os operadores do Direito estão entrevistando de uma maneira parecida com os psicólogos. Indicaram que o trabalho do/a psicólogo/a está servindo para a modelação dos comportamentos dos operadores do Direito. Nesse sentido, há um crescente reconhecimento da Psicologia no âmbito judiciário.

Sendo assim, o subtema Reconhecimento da Psicologia se refere à percepção desses profissionais perante o reconhecimento da Psicologia pelo Direito. Três participantes $(2,4$ e 7$)$ indicaram que os operadores do Direito estão sendo abertos e acessíveis ao conhecimento psicológico e, assim, valorizando a Psicologia.

O subtema Integração da rede se refere às opiniões dos participantes acerca de uma reestruturação da rede de proteção para crianças e adolescentes. Um participante (6) questionou se algumas instituições, como o Centro de Referência de Assistência Social (CRAS) e o Centro de Referência Especializado em Assistência Social (CREAS), precisam realmente ouvir crianças e adolescentes com notificações de violência sexual. Apontou, assim como outra participante (2), que a fala em vários lugares gera a revitimização da criança ou adolescente. Além disso, a participante (2) enfatizou a necessidade de uma capacitação para a rede, com o objetivo de reduzir a fala de crianças e adolescentes na fase pré-processual.

O tema Sentimentos diz respeito ao que a prática do DE desperta nos psicólogos que a realizam. Uma participante (4) relatou não gostar de atuar no DE, pois a situação de violência sexual e o sofrimento em que a criança ou adolescente vítima está passando causa muita 
angústia. Além disso, apesar de saber que não é função do/a psicólogo/a dizer se a violência aconteceu ou não, verbalizou ser muito difícil internalizar isso. Outra participante (9) relatou não considerar o DE como uma das atividades profissionais que mais lhe traz prazer. De acordo com a participante, atuar no DE é um "trabalho pesado", que exige bastante emocionalmente. Outra participante (10) relatou sentir desconforto em sua atuação no DE, por ser uma prática com muita exposição, mas não consegue ver outra forma que poderia ser realizado, sem que a criança ou adolescente fosse ouvida pelo/a juiz/a. Por outro lado, uma participante (7) relatou gostar muito de trabalhar no $\mathrm{DE}$, pois não tem uma rotina, cada DE é único.

O tema Agilidade é referente a compreensão dos psicólogos do DE como uma prática mais ágil do que a audiência tradicional. Esse tema possui dois subtemas: Antecipação da oitiva e Responsabilização dos agressores.

O subtema Antecipação da oitiva, como o nome indica, é referente à oitiva de crianças e adolescentes antecipada em comparação ao formato tradicional. Um participante (1) relatou que anteriormente ao DE, a média era de dois anos após os fatos e, atualmente, as entrevistas são realizadas dentro do mesmo mês. Além disso, uma participante (6) apontou a Lei n. 13.431/2017 como um avanço que vem auxiliar na agilidade das oitivas de criança e adolescentes no judiciário.

O subtema Responsabilização dos agressores corresponde à agilidade da responsabilização dos agressores pelo cometimento da violência sexual contra crianças e adolescentes. Uma participante (5) apontou que a maior vitimização para a criança ou o adolescente é a demora entre a denúncia e o julgamento. Nesse sentido, duas participantes (2 e 3) relataram que a fala da vítima é muito importante, normalmente sendo a única testemunha do crime, para que se possa condenar quem é culpado/a e absolver quem é inocente. Porém, um participante (6) considerou que as provas indiciária e judicial poderiam ser condensadas, para que não fosse necessário repetir o que foi feito na prova indiciária, na prova judicial.

O tema Proteção se refere à compreensão dos participantes sobre a prática do DE como protetiva para crianças e adolescentes. Alguns participantes (2, 3, 5 e 9) relataram que o DE diminui a revitimização e reduz os danos às crianças e aos adolescentes. Além disso, três participantes $(7,8$ e 10) indicaram que a oitiva no formato do DE possibilita encaminhamentos e outras medidas protetivas que julguem necessárias.
Dois participantes (2 e 7) enfatizaram o afastamento do/a agressor/a da vítima como um dos maiores pontos protetivos do DE. Além de proteção para a vítima, esses participantes indicaram que a responsabilização do/a agressor/a se torna protetiva para a sociedade. Tanto evitando que essa pessoa violente alguma outra criança ou outro adolescente, quanto para diminuir o senso da impunidade presente na sociedade, reforçando a importância da notificação e da denúncia. Uma participante (10) apontou que o DE é protetivo também para a família da vítima, pois, em alguns casos, a violência ocorre de geração em geração dentro dessa família. Indicou que o DE pode auxiliar no rompimento da violência sexual naquela família.

Alguns participantes (1, 3, 5, 6 e 9) indicaram a prática do DE como protetiva, principalmente em comparação ao formato de audiência tradicional. Relataram que a criança ou adolescente era usado como objeto de coleta de provas. Apontaram que a presença da vítima em ambiente de sala de audiência tradicional a deixaria exposta a qualquer tipo de pergunta e isso seria muito danoso.

Por fim, três participantes (1, 7 e 10) indicaram que a ausência do/a réu/ré no DE é um fator extremamente importante para a proteção das crianças e adolescentes. Um participante (1) relatou que, apesar da Lei n. 13.431/2017 prever que o/a entrevistador/a do DE possa indicar que não é adequado a presença do/a réu/ré na sala de audiências, a presença do/a imputado/a deveria ser vedada no dia do DE, pois não é o momento em que o/a réu/ré vai ser escutado/a e que, além disso, o DE é gravado e ele/a pode assistir posteriormente.

O último tema resultante da análise de dados, Legislação, refere-se aos posicionamentos dos participantes sobre a legislação acerca da escuta de crianças e adolescentes no judiciário, mais especificamente a Lei n. 13.431/2017. Esse tema possui um subtema: Posicionamento CFP.

A maioria dos participantes $(1,3,4,5,6,7,8$ e 9) é favorável à legislação aprovada em Abril de 2017. Alguns participantes (1, 4 e 5) relataram que a sua atuação no DE já era próxima do que a legislação prevê, antes mesmo de sua aprovação. Uma participante (7) relatou que a nova legislação vai dar uma visibilidade para a Psicologia, pois todas as crianças e adolescentes deverão ser ouvidos nesse formato (i.e., DE).

Uma participante (10) verbalizou não ter opinião formada sobre a legislação, pois acredita que os profissionais estão assustados em como a legislação será 
operacionalizada. Segundo ela, profissionais “acoados" não conseguirão cumprir o objetivo de proteger as crianças e adolescentes no judiciário. Por isso, indicou que a autonomia do profissional precisa ser resguardada.

Um participante (6), apesar de indicar ser favorável à nova lei, ponderou que a aplicação dela pode se tornar um desafio. Considerando a necessidade de equipes maiores, e de treinamento para esses profissionais, pela maior demanda que trará a efetivação da lei. Além disso, pontua a questão do orçamento para execução da lei, não previsto nela, podendo gerar empecilhos em relação à equipagem dos Tribunais de Justiça para a realização do DE. O participante questionou, ainda, a criação dos centros integrados que a legislação prevê, pois não é algo apenas legal, mas sim que necessitará de um pacto de fluxo com vários atores da rede de proteção e de responsabilização.

Por fim, o subtema Posicionamento do CFP retrata as opiniões de dois participantes (6 e 7) sobre a contrariedade do CFP à atuação dos psicólogos no DE. Uma participante (7) indicou se tratar de uma relação de poder, em que a Psicologia não pode se submeter a práticas que não sejam previamente restritas a ela. Outro participante (6), no entanto, não concordou com as discussões vindas do conselho de classe e da justiça. Relatou considerar sem sentido essas brigas sobre qual categoria profissional pode ou não atuar no $\mathrm{DE}$, pois esses debates não contribuem em nada.

\section{Discussão}

O objetivo deste estudo foi conhecer as opiniões de psicólogos brasileiros que atuam com o DE sobre essa prática. Para tal, foram entrevistados 10 psicólogos de seis estados brasileiros, sendo possível identificar seis temas principais em suas falas.

Os resultados deste estudo demonstraram opiniões sobre a formação do/a entrevistador/a no DE, de acordo com as já descritas na literatura científica. Alguns participantes relataram que $\mathrm{o} / \mathrm{a}$ profissional entrevistador/a no DE pode ser de outras áreas além da Psicologia, desde que tenha capacitação necessária. Esse resultado é consoante a uma pesquisa que indica que com treinamento específico para tal função assistentes sociais, psiquiatras e profissionais da educação também podem atuar no DE (Pelisoli \& Dell'aglio, 2016). Em um estudo com profissionais da saúde $(n=$ 9) e operadores do direito $(n=6)$, foi constatado que, por mais que os profissionais da saúde possam ser os mais preparados, ainda há falta de capacitação. Foi indicada que a necessidade de capacitação específica para execução do DE se sobressai à formação universitária (Froner \& Ramires, 2009).

Mesmo que estudos anteriores (Froner \& Ramires, 2009; Pelisoli \& Dell'aglio, 2016) indiquem que a capacitação específica propicie que profissionais de diferentes formações atuem no DE, a maioria dos participantes deste estudo indicou que os psicólogos são os profissionais mais capacitados para essa tarefa. Assim como salientado em outros estudos (Pelisoli \& Dell'aglio, 2014, 2016), são os psicólogos que possuem conhecimento em desenvolvimento humano, técnicas de entrevista e dinâmica da violência sexual. Além disso, possuem a sensibilidade e habilidade necessárias para conquistar a confiança das crianças e adolescentes (Pelisoli \& Dell'aglio, 2016). Com relação a essa sensibilidade do/a entrevistador/a, há estudo indicando que os operadores do Direito não possuem a sensibilidade necessária e linguagem adequada para essa atuação (Caribé \& Lima, 2015).

Os resultados do presente estudo enfatizaram a importância de uma postura de "continência" do/a profissional perante as crianças e os adolescentes. Assim como salientado em outro estudo, o/a psicólogo/a na oitiva de crianças e adolescentes promove um atendimento adequado à fase de desenvolvimento da vítima proporcionando acolhimento a ela nessa situação desagradável (Abdallah \& Froelich, 2017). Entretanto, os resultados indicaram não ser suficiente a graduação em Psicologia, sendo necessária formações específicas em técnicas de entrevista e dinâmica de violência sexual, para a atuação ideal dos psicólogos no DE. A constante atualização e capacitação técnica, além de habilidades pessoais, são destacadas frequentemente em estudos sobre a temática (Pelisoli \& Dell'aglio, 2014; Pelisoli \& Dell'aglio, 2016).

Os resultados deste estudo indicam que a maioria dos psicólogos utiliza protocolos de entrevista no DE, entre eles o NICHD (National Institute of Child Health and Human Development). O NICHD é o protocolo mais estudado e usado mundialmente. Foi desenvolvido com base em aspectos do desenvolvimento infantil, da memória e de sugestionabilidade, bem como levando em consideração os efeitos do estresse e trauma, o comportamento dos entrevistadores e boas práticas de entrevista. Estudos realizados com o protocolo indicam que é necessário o treinamento dos profissionais para sua utilização. A partir do treinamento, há aumento das informações obtidas por meio de perguntas abertas, que 
proporcionam a recordação livre do evento traumático, diminuindo efeitos de sugestionabilidade (La Rooy et al., 2015). Esse resultado confirma a necessidade da capacitação para a utilização de protocolos durante o DE. De acordo com a Lei n. 13.431 (Brasil, 2017), protocolos de entrevista devem ser utilizados no DE, porém, a lei não delimita quais protocolos. Portanto, permite a autonomia dos psicólogos para que possam escolher o instrumento com o qual mais se identificam. Importante frisar que, como em qualquer área de atuação, o instrumento escolhido pelo/a psicólogo/a, deve ter evidências empíricas de efetividade.

Em relação à autonomia dos psicólogos, os resultados indicam que, de modo geral, os participantes consideram ter conquistado sua autonomia profissional, obtendo liberdade em adaptar as questões para as crianças e adolescentes. Nos poucos casos em que as adaptações não são aceitas pelo judiciário, deve-se à rigidez dos operadores do Direito e à existência de uma hierarquia delimitada no judiciário. Esse resultado está de acordo com outro estudo com profissionais do judiciário do Rio Grande do Sul (Pelisoli \& Dell'aglio, 2016).

Quanto à relação interdisciplinar entre Psicologia e Direito, as opiniões foram divergentes. Alguns participantes acreditavam que, assim como a autonomia, essa relação também varia de acordo com cada operador/a do Direito e com a relação hierárquica existente no judiciário. Assim como constatado em outro estudo (Pelisoli \& Dell'aglio, 2016), os profissionais do Direito que valorizam as especificidades da Psicologia possibilitam maior liberdade para os psicólogos.

Os resultados sobre relação interdisciplinar entre Psicologia e Direito podem indicar um avanço em relação à participação de psicólogos no DE uma vez que o CFP (2010b) destacou que a atuação desses profissionais não deveria estar subordinada tecnicamente a profissionais de outras áreas. Inicialmente, a participação de psicólogos no DE poderia ter um caráter menos autonômo. No entanto, com o passar dos anos, tais profissionais podem ter conquistado maior espaço, integrando-se de forma mais efetiva às equipes multidisciplinares e mostrando suas contribuições à prática do DE. Tendo em vista a formação dos psicólogos e a capacitação para a realização do DE, questionam-se posicionamentos contrários à sua participação nessa prática - deveria o/a psicólogo/a apenas trabalhar na clínica ou ir ao encontro das pessoas nos contextos onde pode contribuir com suas diversas possibilidades de atuação?
Alguns participantes consideraram boa e respeitosa a relação com os operadores do Direito e avaliam ser necessária essa relação para a realização do DE. Esse resultado se faz presente em outro estudo que considera a interdisciplinaridade como uma interação necessária em situações de violência (Fröner \& Ramires, 2009). No entanto, mesmo a interdisciplinaridade sendo necessária, há posicionamentos contrários à atuação de psicólogos no DE. Considera-se que o direito da criança em ser ouvida no judiciário se tornaria um dever, sendo que a atuação do/a psicólogo/a no DE seria desvirtuada, não sendo terapêutica, mas apenas com o intuito de obtenção de provas (Brito, 2008). Embora críticas sejam necessárias ao aperfeiçoamento do DE, percebe-se que estas são advindas de posicionamento pessoal, uma vez que o artigo de Brito (2008) não trata-se de estudo empírico. Questiona-se, portanto, por que não utilizar os conhecimentos da Psicologia no DE tendo em vista colaborar para a não revitimização da criança em audiências tradicionais. Considera-se que o campo de atuação da Psicologia é amplo e diverso, não se restringindo à atuação terapêutica.

Críticas a qualquer prática são necessárias ao seu aperfeiçoamento. Os resultados do presente estudo indicaram possíveis mudanças necessárias no DE. Dentre elas, destaca-se a sugestão do recebimento, pelos psicólogos, das perguntas para as crianças e adolescentes anteriormente ao início do DE. Isso para que exista maior tempo na formulação delas e ainda para que a vítima não fique aguardando o/a psicólogo/a ouvir as perguntas. Além disso, maior interlocução entre psicólogo/a e judiciário após término do DE, possibilitando que o/a psicólogo/a possa fazer considerações com base na sua técnica. Tais observações indicam possíveis ajustes na técnica do DE. A aprovação da Lei n. 13.431 (Brasil, 2017), conforme os participantes relataram, é um avanço ao estabelecer o sistema de garantias de direitos da criança e do adolescente vítima ou testemunha de violência. No entanto, os participantes indicaram um possível ajuste específico que poderá ser necessário. Foi sugerido que a lei indicasse previamente a ausência do/a réu/ré na sala das audiências, pois a lei menciona apenas que $\mathrm{o} / \mathrm{a}$ profissional entrevistador/a, se considerar necessário, poderá solicitar para que $\mathrm{o} / \mathrm{a}$ réu/ré não permaneça na sala de audiências. Os participantes desta pesquisa consideraram que não é necessária a presença do/a réu/ré no dia do DE, pois mantém seu direito de ampla defesa resguardado com a presença do/a seu/sua advogado/a e pode assistir ao DE posteriormente. 
Os resultados apontam que alguns sentimentos são despertados nos psicólogos que atuam no DE. Há a existência de angústia perante a situação complexa de violência sexual contra crianças e adolescentes e o desconforto da exposição de seu trabalho. Além disso, o sentimento de impotência com a impossibilidade de concluir se a violência ocorreu de fato ou não. Esse sentimento de impotência é trazido em um estudo que compreende como uma limitação da Psicologia pela complexidade da situação de violência sexual. Conclui que é uma ciência que, por meio de técnicas e instrumentos, visa corroborar indicativos do fato, mas não tem condições de trazer conclusões (Pelisoli \& Dell'aglio, 2014).

Os participantes consideram o DE como uma prática ágil, tanto na antecipação da oitiva quanto na responsabilização dos agressores. Relataram que as entrevistas no formato do DE são realizadas mais rapidamente do que eram nas audiências tradicionais. Esse resultado é apontado em um estudo de análise de 71 processos jurídicos do Rio Grande do Sul. No estudo, foi verificado que $65,9 \%$ dos processos permaneceram mais de um ano no Ministério Público e 35,3\% mais de cinco anos (Habigzang, Azevedo, Koller, \& Machado, 2006). Além disso, os participantes do presente estudo acreditam que o DE agiliza o tempo entre a denúncia e o julgamento, agilizando também a responsabilização dos agressores. A agilidade na oitiva de crianças e adolescentes é um dos objetivos da Lei n. 13.341 (Brasil, 2017).

Outro resultado deste estudo é a compreensão do DE como uma prática mais protetiva para crianças e adolescentes. Segundo os psicólogos entrevistados, esse formato é muito mais protetivo que uma oitiva em audiência tradicional. Esse resultado indica que a proteção para crianças e adolescentes, um dos principais objetivos da criação do DE, vem ocorrendo na prática (Daltoé, 2007). Os participantes destacaram a possibilidade de realizar encaminhamentos e demais medidas protetivas que julguem necessárias, como um dos pontos mais protetivos no DE. Esse resultado contraria a compreensão de que o psicólogo no DE tem função de obter provas para o judiciário em detrimento da proteção das crianças e adolescentes (Brito, 2008).

A respeito da Lei n. 13.431 (Brasil, 2017), a maioria dos psicólogos indicou ser favorável à nova legislação. Consideraram a lei adequada, pois garante a proteção dos direitos das crianças e adolescentes, versa sobre a autonomia do profissional entrevistador na reformulação de perguntas e utilização de protocolos de entrevista. Entretanto, os resultados deste estudo indicam alguns questionamentos sobre a efetivação da Lei n. 13.431(Brasil, 2017), dentre eles, a falta de garantia de disponibilidade de orçamento necessário para que os Tribunais de Justiça adquiram a estrutura necessária para o DE, aumento de profissionais e sua capacitação, bem como para a reestruturação de fluxo da rede de proteção para a constituição dos centros integrados que a lei prevê. A questão do orçamento se torna ainda mais importante diante do atual cenário de corte de verbas pelo governo federal.

Recentemente, foi anunciado corte de orçamento federal para o Sistema Único de Assistência Social (SUAS). Em 19 de Julho de 2017, foi divulgada a resolução 12, do Conselho Nacional de Assistência Social (CNAS), que prevê orçamento de $\mathrm{R} \$ 59$ bilhões para o SUAS em âmbito nacional, no ano de 2018 (CNAS, 2017). No entanto, o Ministério do Planejamento aprovou orçamento de apenas 78 milhões. De acordo com o movimento social MaisSUAS (2017), esse orçamento inviabilizaria as ações do SUAS em âmbito nacional, tendo em vista o orçamento indicado pelo CNAS. Questiona-se, portanto, o quanto a aprovação da lei por si só garantirá a maior integração do sistema de garantia de direitos de crianças vítimas e testemunhas de violência sem que haja o necessário investimento financeiro para tal.

A contrariedade do CFP sobre a atuação de psicólogos no DE foi considerada por alguns participantes um debate "sem sentido", além de uma relação de poder entre profissões, uma vez que o CFP considera que a Psicologia estaria submetida a outras profissões durante o DE. Essa relação de poder e autonomia acaba por negligenciar o fato de que o DE é um método diferenciado de oitiva em constante construção. Com ou sem ele, as crianças e adolescentes continuarão sendo depoentes nos processos que as impliquem, então, deve-se discutir qual é o modelo mais apropriado para tal (Zotto \& Mehl, 2017). Mesmo sendo contrário ao $\mathrm{DE}$, o CFP não indica outro método que considera mais adequado.

Por fim, este estudo se soma a demais estudos empíricos realizados previamente com o objetivo de fomentar o conhecimento científico acerca do DE (e.g., Pelisoli \& Dell'aglio, 2014; Pelisoli \& Dell'aglio, 2016). A realização de um estudo com psicólogos de diferentes estados brasileiros e com abordagem específica da Lei n. 13.431 (Brasil, 2017) podem ser considerados como avanços em relação aos estudos prévios. Contudo, destaca-se como possível limitação deste estudo 
o fato de aqueles profissionais que possuem opiniões divergentes sobre o DE não terem aceitado participar da coleta de dados. É possível que esses profissionais não se sintam à vontade para compartilhar suas percepções, os tornando menos propensos à participação de pesquisas. Portanto, é necessária a continuidade dos estudos sobre as percepções dos profissionais acerca do DE visando abranger todos aqueles que trabalham com essa prática.

\section{Referências}

Abdallah, Z. N. L., \& Froelich, H. L. (2017). O profissional psicólogo na fase processual do depoimento sem dano. Revista Brasileira de Psicologia, 04(01), 52-61. Recuperado dehttps://portalseer.ufba.br/index. $\mathrm{php} / \mathrm{revbraspsicol} /$ issue/download/1843/495

Brasil (1990a). Lei n. 8.069, de 13 de julho de 1990. Recuperado de http://www.planalto.gov.br/ccivil_03/ leis/L8069.htm

Brasil (1990b). Lei n. 99.710, de 21 de novembro de 1990. Recuperado de http://www.planalto.gov.br/ccivil_03/decreto/1990-1994/d99710.htm

Brasil (2017). Lei n. 13.431, de 4 de abril de 2017. Recuperado de http://www.planalto.gov.br/ccivil_03/_ato2015-2018/2017/lei/L13431.htm

Braun, V., \& Clarke, V. (2006). Using thematic analysis in psychology. Qualitative Research in Psychology, 3(2), 77-101. doi:10.1191/1478088706qp063oa

Brito,L.M. T. (2008). Diga-me agora... o depoimento sem dano em análise. Psicologia Clínica Rio de Janeiro, 20(2), 113-125. doi:10.1590/S0103-56652008000200009

Caribé, J. de B., \& Lima, I. M. S. O. (2015). Depoimento sem dano: Proteção integral da criança vítima de abuso sexual intrafamiliar. Journal of Human Growth and Development, 25(1), 108-116. doi:10.7322/ jhgd.96801

Conselho Federal de Psicologia (2010a). A escuta de crianças e adolescentes envolvidos em situação de violência e a rede de proteção. Brasília: DF.

Conselho Federal de Psicologia (2010b). Resolução n. 010/2010. Recuperado de http://site.cfp. org.br/wp-content/uploads/2010/07/resolucao2010_010.pdf

Conselho Federal de Psicologia (2018). Nota técnica nº1/2018/GTEC/GC. Brasília: Conselho Federal de Psicologia. Recuperado de https://site.cfp.org. br/wp-content/uploads/2018/01/NOTA-TECNICA-N\%C2\%BA-1_2018_GTEC_CG.pdf

Conselho Nacional de Assistência Social (2017). Resolução $n^{\circ}$ 12/2017. Recuperado de http:// www.mds.gov.br/cnas/legislacao/resolucoes/ arquivos-2017/resolucoes-2017/

Conselho Nacional de Saúde (2016). Resolução 510/ 2016. Recuperado de http://conselho.saude.gov.br/resolucoes/2016/Reso510.pdf

Daltoé, C. J. A. (2007). Depoimento sem dano: Uma alternativa para inquirir crianças e adolescentes nos processos judiciais. Porto Alegre, RS: Livraria do Advogado.

Flick, U. (2009). Pesquisa qualitativa online: A utilização da internet. Em U. Flick (Ed.), Introdução à Pesquisa Qualitativa (pp. 238-253). Porto Alegre, RS: Artmed.

Fröner, J. P., \& Ramires, V. R. R. (2009). A escuta de crianças vítimas de abuso sexual intrafamiliar na concepção de profissionais que atuam no âmbito do Judiciário. Psicologia em Revista, 15(3), 60-81. Recuperado de http://pepsic. bvsalud.org/scielo.php?script=sci_arttext\&pid $=$ S1677-11682009000300005

Habigzang, L. F., Azevedo, G. N. A., Koller, S. H., \& Machado, P. X. (2006). Fatores de risco e proteção na rede de atendimento a crianças e adolescentes vítimas de violência sexual. Psicologia: Reflexão e Crítica, 19(3), 379-386. doi:10.1590/ S0102-79722006000300006

La Rooy, D. J., Brubacher, S. P., Aromäki-Stratos, A., Cyr, M., Hershkowitz, I., Korkman, J.,... Lamb, M. (2015). The NICHD protocol: A review of an internationally-used evidence-based tool for training child forensic interviewers. Journal of Criminological Research, Policy and Practice, 1(2), 76-89. doi: 10.1108/JCRPP-01-2015-0001

MaisSUAS (2017). Orcamento suas 2018 do governo federal inviabiliza assistência social no país. Recuperado de https://maissuas.org/2017/09/08/ orcamento-suas-2018-do-governo-federal-inviabiliza-assistencia-social-no-pais/

Pelisoli, C., \& Dell'aglio, D. D. (2014). Psicologia jurídica em situações de abuso sexual: Possibilidades e desafios. Boletim de Psicologia, 63(139), 175-192. Recuperado de http:/ / 
pepsic.bvsalud.org/scielo.php?script=sci_arttext\& pid=S0006-59432013000200006

Pelisoli, C., \& Dell'aglio, D. D. (2016). A humanização do sistema de justiça por meio do Depoimento Especial: Experiências e desafios. Psico USF, 21(2), 409-421. doi: 10.1590/1413-82712016210216

Pelisoli, C., Dobke, V., \& Dell'aglio, D. D. (2014). Depoimento Especial: Para além do embate e pela proteção das crianças e adolescentes vítimas de violência sexual. Temas em Psicologia, 22(1), 25-38. doi:10.9788/TP2014.1-03

Santos, B. R., dos \& Gonçalves, I. B. (2009). Depoimento Sem Medo (?): culturas e práticas não revitimizantes: Uma cartografia das experiências de tomada de depoimento especial de crianças e adolescentes. São Paulo, SP: Childhood Brasil. Recuperado de http://www.childhood.org. br/wp-content/uploads/2013/10/DSM_Livro_ portugues1.pdf
Summit, R. C. (1983). The child sexual abuse accommodation syndrome. Child Abuse \& Neglect, 7, 177-193. doi:10.1016/0145-2134(83)90070-4

Tribunal Regional Federal da 2a . Região (2016). TRF2: Conselhos de Psicologia não podem proibir profissionais de intermediar inquirição de crianças e adolescentes na justiça. Recuperado de https:// www10.trf2.jus.br/portal/trf2-conselhos-de-psicologia-nao-podem-proibir-profissionais-de-intermediar-inquiricao-de-criancas-e-adolescentes-na-justica/

Zotto, A. R. D., \& Mehl, T. G. (2017). O depoimento sem dano e a atuação do psicólogo jurídico. Revista de Iniciação Científica, Criciuma, 15(2). Recuperado de http://periodicos.unesc.net/iniciacaocientifica/ article/view/3741

Recebido em: 19/02/2019

Reformulado em: 17/02/2020

Aprovado em: 23/03/2020

Nota dos autores:

O estudo foi realizado com apoio da Fundação de Amparo à Pesquisa do Rio Grande do Sul (FAPERGS), por meio do edital 01/2017 - Apoio a Recém Doutor (ARD), e da Fundação IMED, por meio de bolsa produtividade concedida ao segundo autor.

Sobre os autores:

Janaina Alessandra da Silva Sanson é Psicóloga (IMED, 2018). Atua na clínica privada. É perita nomeada pelo juiz para avaliações psicológicas em Vara de Família e no Juizado da Infância e Juventude.

ORCID: http://orcid.org/0000-0001-8641-8480.

E-mail: janainasanson@outlook.com

Jean Von Hohendorff é Psicólogo (FACCAT, 2009), mestre (2012) e doutor (2016) em Psicologia (UFRGS), com estágio de pós-doutorado (UFRGS, 2017). É professor do Programa de Pós-Graduação em Psicologia da IMED (Passo Fundo/RS), onde coordena o grupo de pesquisa VIA Redes (Violência, Infância, Adolescência e Atuação das Redes de proteção e de atendimento).

ORCID: http://orcid.org/0000-0002-7414-5312.

E-mail: jhohendorff@gmail.com

Contato com os autores:

Rua General Prestes Guimarães, 304, Vila Rodrigues

Sala do PPG Psicologia

Passo Fundo-RS, Brasil

CEP: 99070-220

Psico-USF, Bragança Paulista, v. 26, n. 1, p. 27-39, jan./mar. 2021 